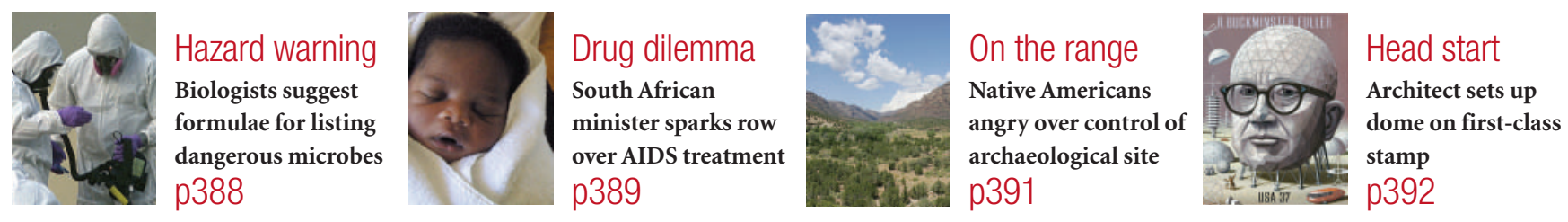

\title{
Los Alamos grinds to a halt after classified information vanishes
}

Rex Dalton, San Diego

In an unprecedented move, all research at Los Alamos National Laboratory (LANL) in New Mexico was shut down on 16 July. The drastic step follows the loss of computerstorage devices, which went missing earlier this month. Instead of doing research, many employees will this week be undergoing extra training while top government officials scrutinize the lab.

It has been a bad month for US nuclearweapons labs - LANL is not the only one to have had security problems. On 15 July, Sandia National Laboratories in New Mexico, which conducts military research, reported losing a classified computer disk, although just a day later officials said that they had found it. But some observers and researchers say that LANL seems to be getting rougher treatment for its security lapses, and wonder if this might be an attempt to swing a future bid for lab management to a different institution.

The loss of the storage devices is LANL's third security failure in eight months. Last December an inventory revealed ten storage devices were missing, then in May it was found that a computer device had been destroyed without proper documentation. In the current case, two missing devices were found misplaced in a high-security area, but two others remained unaccounted for as of 19 July - all came from the weapons physics directorate.

Officials at the University of California (UC), which manages LANL, attribute the security failures to a "cowboy culture" in which some researchers fail to follow policies for managing classified material.

Top officials from the Department of Energy, which owns the labs, arrived this week to help find the missing devices and to rectify problems. They were accompanied by members of the House committee that oversees the national labs, including its chairman Joe Barton (Republican, Texas).

There are about 12,000 employees at Los Alamos, nearly half of whom are scientific staff. During the stand-down, LANL researchers will take inventories of classified material and undergo repeat training exercises. Some research may resume this week.

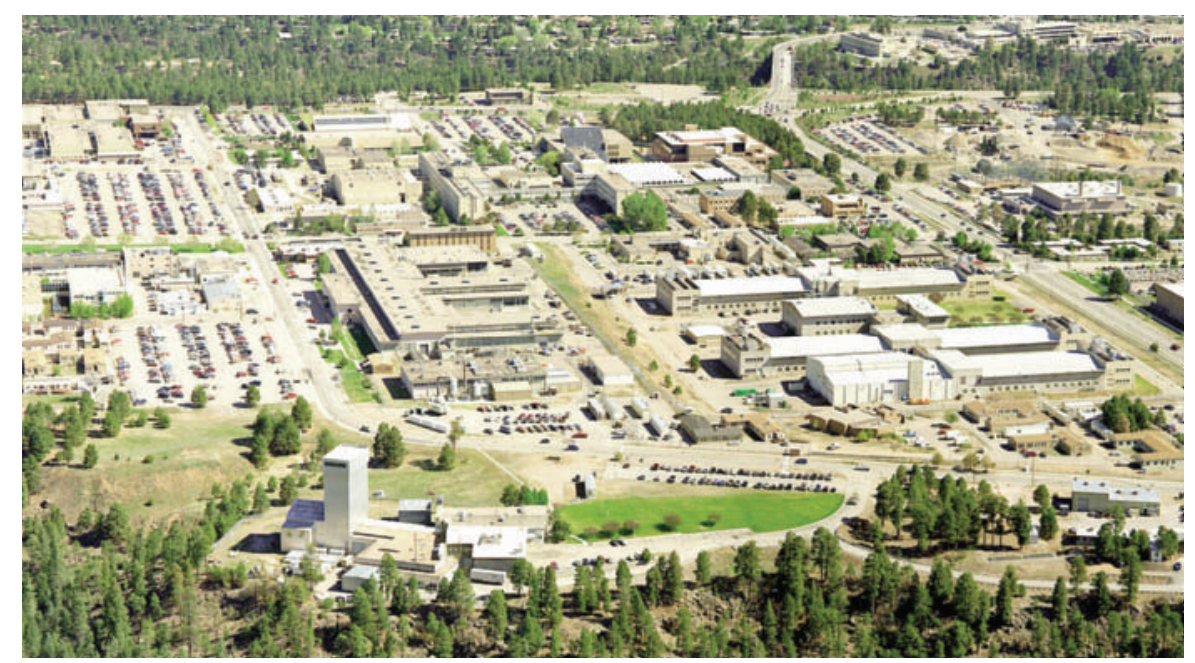

A series of security lapses at Los Alamos National Laboratory have put its management under scrutiny.

Meanwhile, UC officials say that they are intensifying efforts to instil a new culture in which security lapses won't be tolerated. Peter Nanos, LANL's director, wrote a blunt e-mail to staff to emphasize the point: "If you think the rules are silly, if you think compliance is a joke, please resign now." Although similar statements were made after the earlier gaffs, there is a fresh urgency to the comments this month.

\section{Trouble at the top}

The problems come at a bad time for UC, which has managed both LANL and the Lawrence Livermore National Laboratory another nuclear-weapons lab — for decades. Earlier this year, the energy department decided to open the management of both labs to outside bids; proposals for managing LANL will be invited after November's presidential election. The role is coveted by others, including the University of Texas and defence contractor Lockheed Martin.

Congressmen from Texas - particularly Barton - have heavily criticized UC's management of LANL. At a hearing of the House Committee on Energy and Commerce last week, Barton said: “There's probably better security at the public library over CDs and videos." He also demanded that hundreds of lab employees take lie-detector tests.
But when the missing computer disk was announced at Sandia, which is run by Lockheed Martin, Barton was quiet. A spokesman for Barton told Nature that he had no comment on Sandia's problem at this time. Sandia's security lapse was spotted during an annual audit at the end of June, but wasn't made public for two weeks. Lockheed Martin officials say they are tightening procedures.

Such scenarios have prompted some UC professors to wonder whether congressional Republicans and Bush administration officials are trying to play up embarrassing management problems at UC-managed labs, perhaps to aid a Texas bid. Winning the contract to manage a major nuclear-research facility would be a great financial coup for any university. Over the past week, memos detailing past security issues at LANL have been leaked and issues raised about safety incidents, some of which seem routine. "The timing of these events makes people wonder," one LANL researcher told Nature.

UC will be trying hard to bring its staff in line with security rules over the coming months as researchers get back to work. Regardless of who controls the lab in the future, experts say that they will be keen to keep classified material where it belongs not misplaced, missing or wreaking havoc with the lab's public image. 